\title{
Optimization of a Hybrid System Connected with Utility Grid using Homer Software
}

\author{
Israr Uddin ${ }^{1}$, Dr. Adnan Daud khan², Zafar Ahmad ${ }^{3}$, Syed Afzal Shah ${ }^{4}$ \\ 1,2,3,4 Department of Electrical Energy System Engineering, US-Pakistan Center for Advanced Studies in energy \\ (USPCAS-E), UET Peshawar
}

israreneg93@gmail.com ${ }^{1}$, adnan.daud@uetpeshawar.edu.pk ${ }^{2}$, zafar.ahmad619@gmail.com ${ }^{3}$, afxalshaw@gmail.com ${ }^{4}$

Received: 09 December, Revised: 19 December, Accepted: 25 December

\begin{abstract}
A microgrid is a combination of distributed energy sources to generate power to the consumer or exchange electrical energy to the grid or working in a standalone system. The microgrid may be on-grid or off-grid. Distributed Generators (DG, s) are more reliable on-site selection. Therefore, a hybrid energy system came into existence. Like to combine solar PV, wind, small Hydro, and diesel generator and fuels cells. Solar PV, wind and diesel generator hybrid system are more analyzed previously in the research study. In this research PV, Batteries and diesel Gen are combined to make a hybrid system connected to the utility grid, which is economical and reliable. The potential resource data were downloaded from NASA through the homer tool. Homer software is used for the simulation to simulate and analyze the hybrid system.
\end{abstract}

Keywords - DG,s, NASA, IEA, HRES, LOCE, NPC,AC, DC

\section{INTRODUCTION}

As the energy demand is increasing steadily due to industrialization, commercialization needs electricity. The increased demand illustration is one of the problems facing many communities in the world. Also in the coming era, the fossil fuel reserves will also reduce due to which high-cost factor is an issue for the world. International energy agency (IEA) predicted that nearly 1.6 billion billion persons of the world still having no access to power (electricity), also the energy demand will increase $53 \%$ by 2035 [1]. To fulfill the energy demand alternative energy resources are needed to utilize. Also, fossil fuels have many issues related to the environment, economic and lifestyle of a human being. The currently conventional energy sources used for the generation of electrical power are oil, coal and natural gas worldwide. These conventional energy sources have impacts on the environment as well as on human health due to the greenhouse effect are the major disadvantages [2][3].

The global institute researchers and scientists are working to find alternatives to replace conventional sources with renewable energy sources [4]. Since, in the past few years the interest has increased in renewable energy sources like solar PV, wind, micro-hydro, and biogas. These sources have many advantages enviremently as well as on human life [5]. Therefore, to make a system that combines renewable and non-renewable energy sources. Hybrid renewable energy system (HRES) is basically a combination of one or more sources to generate the electrical power either autonomously or connected to grid [6]. Solar and wind system either working autonomously or grid-connected mode however, the efficiency of these sources are less due to unpredictable nature. The hybrid system overcomes this problem to integrate renewables with grid mode to sustain energy [7]. In case of any lack of electrical power in a situation when there is not enough power generated from renewable energy sources diesel generator or battery storage are used for backup [8][9].

Hybrid renewable energy system (HRES) optimization and simulation can be carried out through many software nowadays, such as Homer, Hoga, and hybrid 2 with various backgrounds and simulations. HOMER used an algorithm for the optimization and sensitivity analysis to assess the best feasible system configuration. Homer evaluate both types of system offgrid and grid-connected mode for different application. For a designer, it benefits to find out the optimum system of PV, wind, hydro, batteries, biogas and diesel generator by entering various inputs to the software. It calculates and offers the best optimum system based on feasibility and evaluating life cycle cost which permits the user to find the best system with net present cost to make their own power system. Homer removes a system that is incompetent to fulfill the load demand which is not suitable. Homer also simulates the sensitivity analysis to determine different constraint effects on the power system [10].

The most important benefit of the grid connection is that any sort of uncertainty from renewable will fulfill the Grid. Many researchers have worked on a grid-connected hybrid system. From previous research related work different researcher worked on the HOMER optimization tool for different areas to get the best-optimized configuration. In this paper [11] presented the techno-economic analysis to design a hybrid system composed of PV/wind with a grid connected for an average load demand $15000 \mathrm{kwh} /$ day and the maximum demand is $2395 \mathrm{~kW}$ for Riyadh city in Saudi Arabia. In [12] stated the cost analysis of different hybrid energy systems composed of solar PV, wind and diesel Generator with grid-connected, for an average energy demand of $35 \mathrm{kwh} /$ day and maximum load is $4.1 \mathrm{kw}$ in hilly area of Bangladesh. Most research has installed solar PV and wind in the hybrid system. 
In this research, we selected the sources for our interest is solar PV, Diesel Generator and Batteries with grid-connected mode. To obtain different hybrid configuration from Homer optimization, and to obtain the optimized and economical hybrid system.

\section{METHODOLOGY}

For the hybrid energy system combination, we considered sources like solar PV, Diesel generator and storage batteries with utility grid. As the demand is $\mathrm{AC}$ so we need a converter to convert DC from PV and batteries to AC. The generator is connected to the AC side. For backup generator and storage batteries are used in case of any shortage of power or in peak hours.

\section{A. Load data}

The selected site for the study is Electrical Engineering Department University of Engineering and Technology Peshawar, Khyber Pakhtunkhwa, Pakistan located with latitude 34.01510 N and longitude 71.52490 E. The department consists of classroom, laborites, library and staff offices. HVAC system was installed in all building and lightning of different ranges. The department is open on weekdays from 9.00 am to $5.00 \mathrm{pm}$ and it seems the load is high in these hours, because of the department schedule. The average daily load demand is $574.6(\mathrm{kwh} /$ day $)$ and maximum deand is $99.66 \mathrm{KW}$. The load demand of daily profile is shown in fig-1.

\section{Daily Profile}

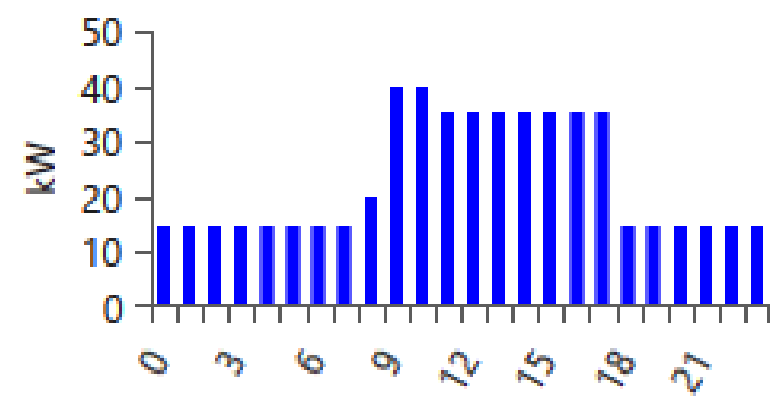

Figure 1. Daily profile of load demand

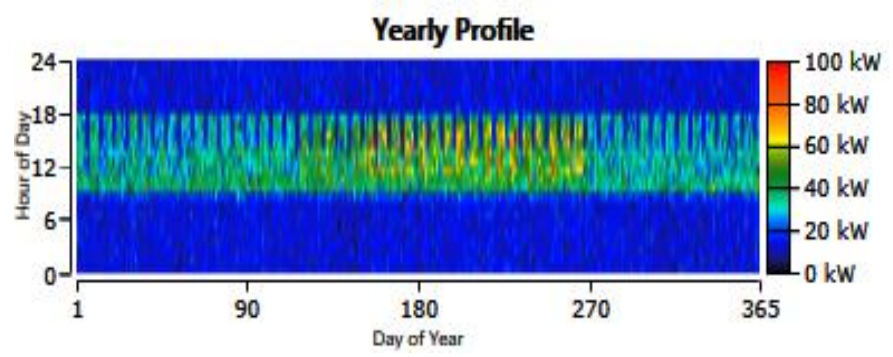

Figure 2. Yearly profile of load demand

The selected site is in the area which is very hot in summer and very cold in the winter period. However, the demand is high in summer because of the HVAC system which combines in summer periods. The yearly load profile is shown in figure- 2 .

\section{B. Resource potential}

Peshawar is located in the region where solar potential is remarkable. The resource potential is shown in fig-3. The resource potential is downloaded from NASA online through Homer software. The highest solar radiation is in June and the lowest is in December. While the average is $5.02 \mathrm{kWh} / \mathrm{m} 2$.

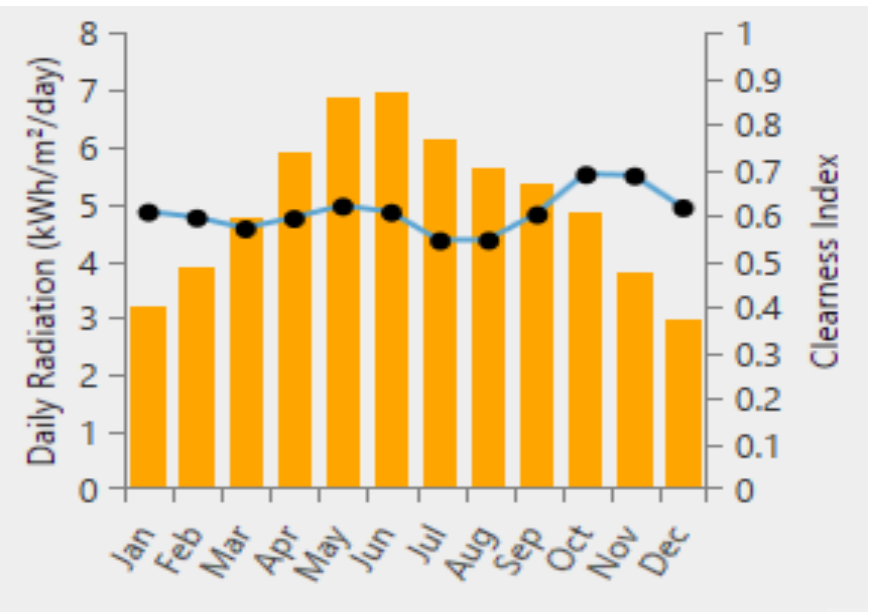

Figure 3. Daily solar insolation -(GHI)

\section{System Modeling}

In this hybrid system we have PV, Diesel Generator, and storage batteries connected to utility grid. The Gerator and Grid is linked to the main AC bus, while the Batteries and PV is linked to DC bus. As the load demand is AC so a converter is required to change $\mathrm{DC}$ from batteries and $\mathrm{PV}$ to $\mathrm{AC}$. The schematic diagram of our proposed model is given in fig- 4 .

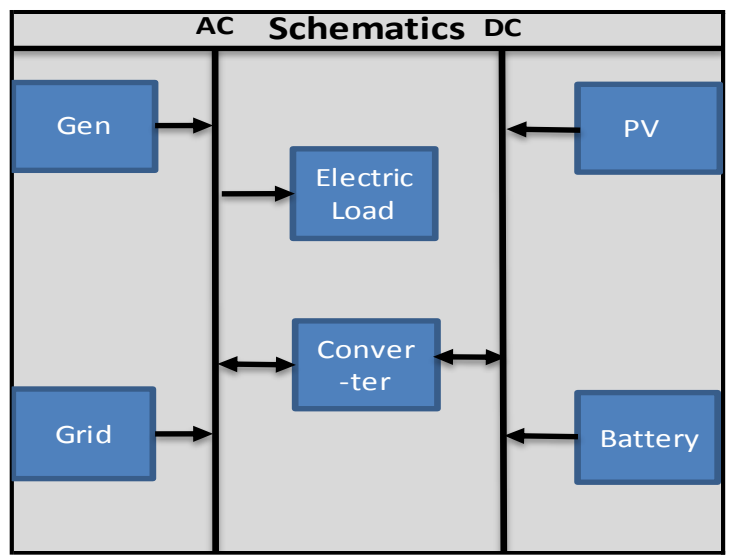

Figure 4. Proposed Model of HRES Schematic

\section{RESUlTS AND DISCUSION}

After the putting all the inputs for the homer simulation we get the results as shown in fig- 5 . The homer give the optimized configuration of different combination but we will select the HRES Configuration with lowest cost of energy (LOCE) and net present cost (NPC) . 


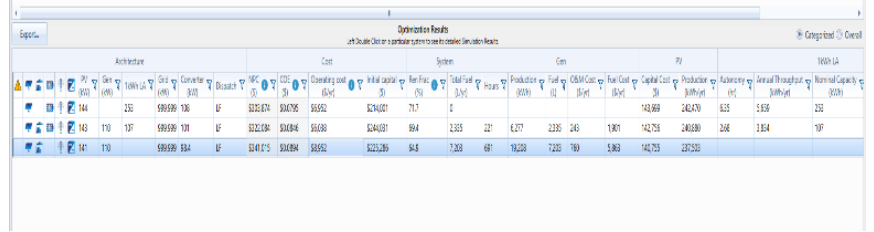

Figure 5. Simulated Results of differtent HRES

From the simulation the best optimized configuration is the 1st on which is the combination of PV, Battery and Grid. PV and Grid are the main sources which fulfill the primary load demand, while the Battery is used for backup in case when there is load not meet up. The electrical generation throughout the year of PV and grid is given in fig- 6 .

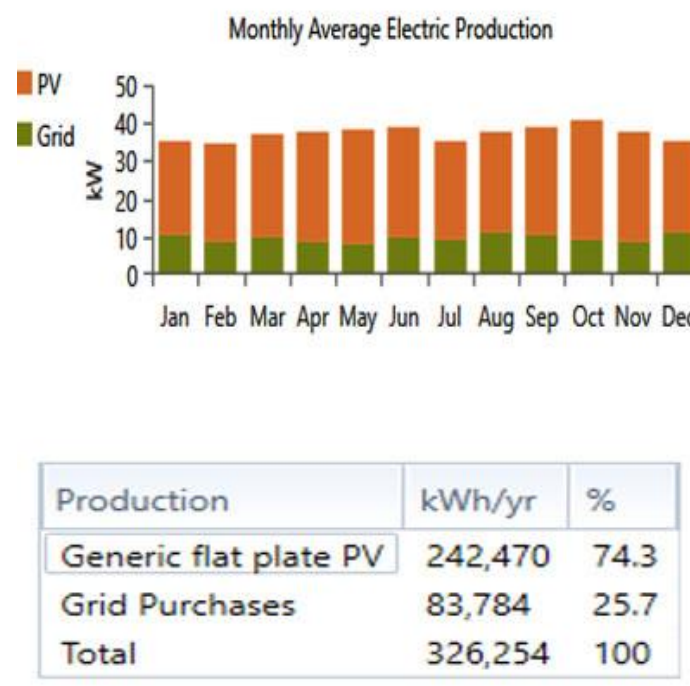

Figure 6. MonthlyAverage Electrical generated (PV, Grid)

Electrical production from the battery energy storage is shown in figure-7.

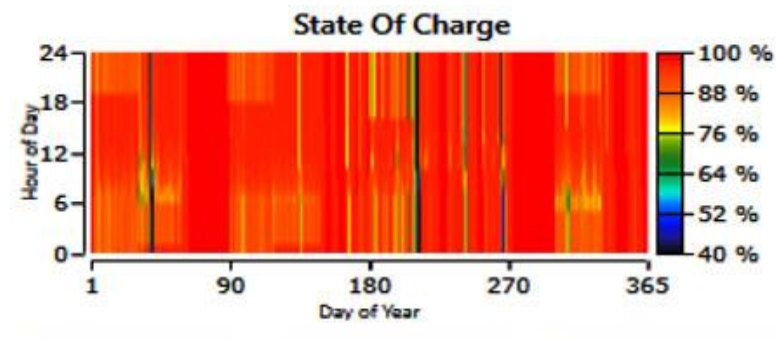

\begin{tabular}{|l|l|}
\hline Quantity & Value Units \\
\hline Batteries & 253 qty. \\
\hline String Sce & 1.00 batteris \\
Strings in Parallel & 253 stings \\
Bus Voltage & $120 \mathrm{~V}$ \\
\hline
\end{tabular}

\begin{tabular}{|c|c|c|c|c|c|}
\hline Quartity & Value & Uni & Quantity & Value & Units \\
\hline Autonomy & 25 & $\mathrm{hr}$ & Average Energy Cost & 0 & S/Wh \\
\hline orage Wear Cost & 0210 & $S A$ & Energy $\mathrm{ln}$ & 6,327 & kWhyr \\
\hline Nominal C & 253 & $\mathrm{kh}$ & Pat & 5,062 & Whyyr \\
\hline Usable I & 152 & $\mathrm{kh}$ & . & 0 & WWh $\}_{3}$ \\
\hline Lifetime Throughput & 56,594 & $\mathrm{kh}$ & 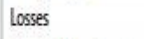 & 1,265 & kWhyr \\
\hline Expected life & 10.0 & yr & Annual Throughput & 5,659 & kWhyr \\
\hline - & & 1 & & & \\
\hline
\end{tabular}

Figure 7. Electrical eenrgy generated from Battery

The system total net present cost, operation \& maintenance cost salvage and replacement cost is shown in figure- 8 .

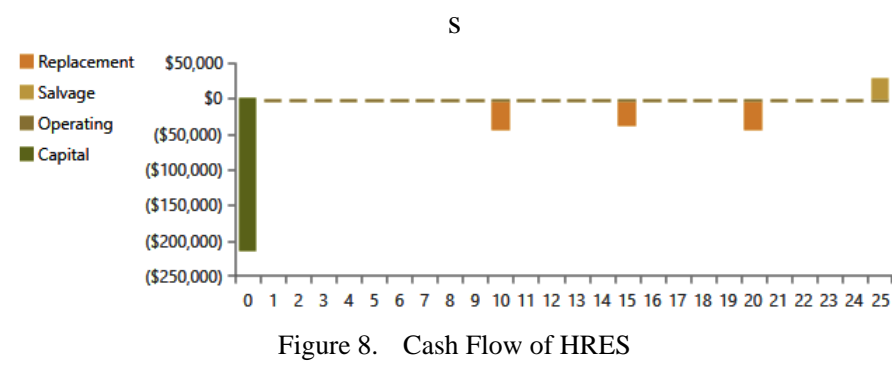

From the above results, we select the first hybrid renewable energy system (HRES) because the net present cost (NPC) of the system and lowest cost of energy (LOCE) is low as compared to other HRES system configuration.

\section{CONCLUSION}

The researchers has a great intention towards to the increased interest in renewable day by day. Many organization are working to penetrate the renewable energy in the current power system in many countries, to meet their load demand. In this research study we have to find the best optimized hybrid renewable energy system (HRES) to fulfill the required load with lowest cost of energy (LOCE). From the results it is evaluated that the best optimized system is Solar PV, batteries and connected with Grid based on lowest cost of energy and net present cost.

\section{REFERENCES}

[1] M. pd. Zerta, P. R. Schmidt, C. Stiller, and H. Landinger, "Alternative World Energy Outlook (AWEO) and the role of hydrogen in a changing energy landscape," Int. J. Hydrogen Energy, vol. 33, no. 12, pp. 30213025, 2008

[2] M. D. A. Al-falahi, S. D. G. Jayasinghe, and H. Enshaei, "A review on recent size optimization methodologies for standalone solar and wind hybrid renewable energy system," Energy Convers. Manag., vol. 143, pp. 252-274, 2017

[3] Y. Z. Alharthi, M. K. Siddiki, and G. M. Chaudhry, "The New Vision and the Contribution of Solar Power in the Kingdom of Saudi Arabia Electricity Production,” IEEE Green Technol. Conf., pp. 83-88, 2017.

[4] K. Y. Lau, M. F. M. Yousof, S. N. M. Arshad, M. Anwari, and A. H. M Yatim, "Performance analysis of hybrid photovoltaic/diesel energy system under Malaysian conditions," Energy, vol. 35, no. 8, pp. 32453255, 2010 .

[5] M. B. M. Rozlan, A. F. Zobaa, and S. H. E. A. Aleem, "The Optimisation of Stand-Alone Hybrid Renewable Energy Systems Using Integration of Stand Alone Hybrid Renewable Energy Systems Optimisation using HOMER," no. July, 2011.

[6] S. N. Kane, A. Mishra, and A. K. Dutta, "Preface: International Conference on Recent Trends in Physics (ICRTP 2016)," J. Phys. Conf. Ser., vol. 755, no. 1, 2016

[7] V. Khare, S. Nema, and P. Baredar, "Solar - wind hybrid renewable energy system : A review," Renew. Sustain. Energy Rev., vol. 58, pp. 23 33, 2016.

[8] B. S. Borowy and Z. M. Salameh, "Methodology for optimally sizing the combination of a battery bank and PV array in a Wind/PV hybrid system," IEEE Trans. Energy Convers., vol. 11, no. 2, pp. 367-373, 1996.

[9] J. L. Bernal-Agustín and R. Dufo-López, "Simulation and optimization of stand-alone hybrid renewable energy systems," Renew. Sustain. Energy Rev., vol. 13, no. 8, pp. 2111-2118, 2009.

[10] T. Lambert, P. Gilman, and P. Lilienthal, "Micropower System Modeling with Homer,” Integr. Altern. Sources Energy, pp. 379-418, 2006. 
[11] Y. Z. Alharthi, M. K. Siddiki, and G. M. Chaudhry, "Techno-economic analysis of hybrid PV/Wind system connected to utility grid," 2019 IEEE Texas Power Energy Conf. TPEC 2019, pp. 1-6, 2019.

[12] M. Moniruzzaman and S. Hasan, "Cost analysis of PV/wind/diesel/grid connected hybrid systems," 2012 Int. Conf. Informatics, Electron. Vision, ICIEV 2012, pp. 727-730, 2012.

Israr Uddin is a postgraduate researcher at United States Pakistan Center for Advanced Studies in Energy at University of Engineering and Technology Peshawar, Pakistan. He is studying Electrical Energy System Engineering at MS level after doing his undergraduate degree in Electrical (power) Engineering. His research interest include finding the best optimized configuration of hybrid energy system with grid connected using HOMER. This paper is a part of his Master degree research studies. 